
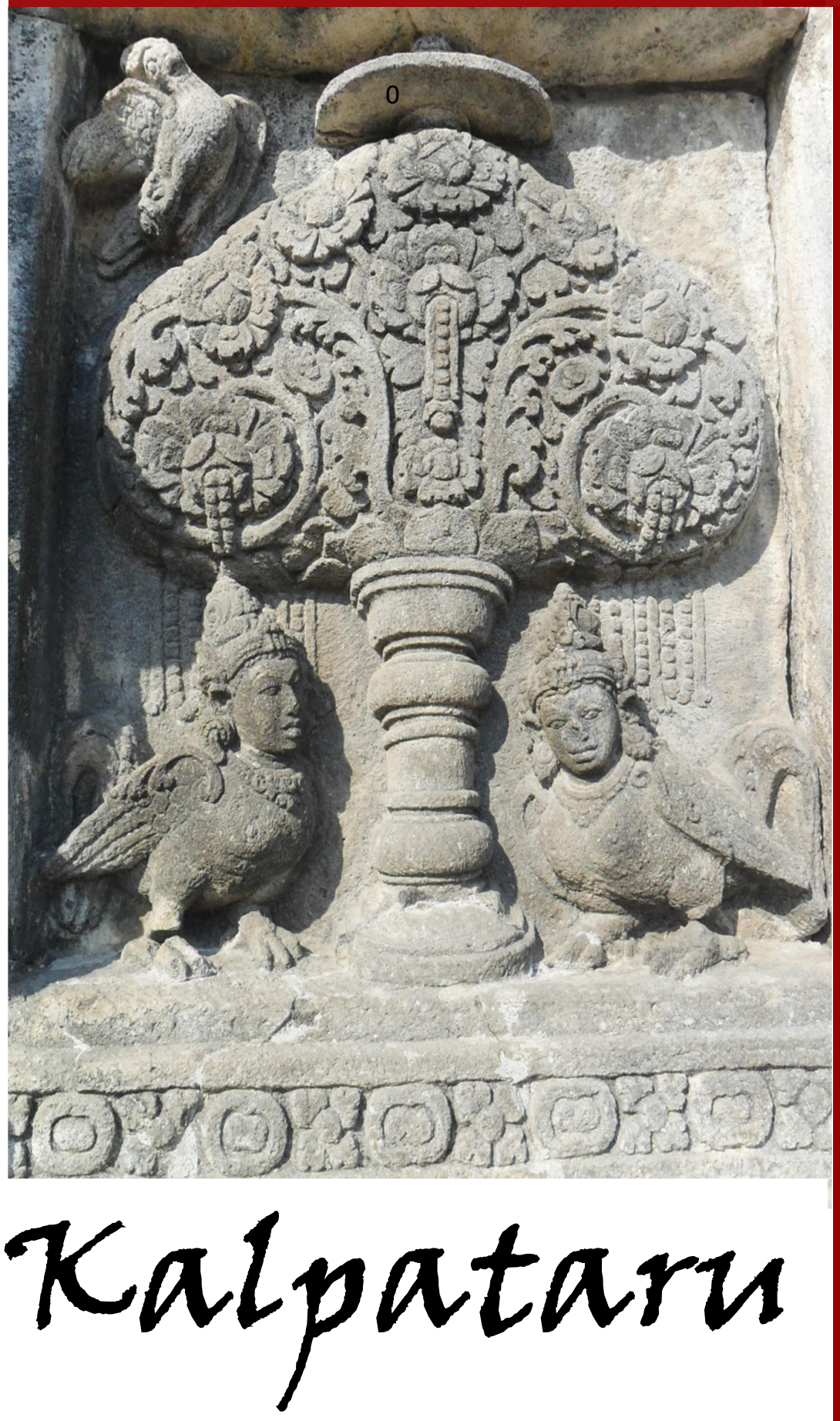

\author{
JURNAL SEJARAH DAN \\ PEMBELAJARAN SEJARAH
}

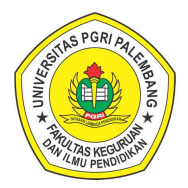

Program Studi Pendidikan Sejarah Jurusan Pendidikan IPS

Fakultas Keguruan dan IImu Pendidikan Universitas Persatuan Guru Republik Indonesia Palembang
Pengaruh Model Pembelajaran Student Facilitator and Explaining Terhadap Hasil Belajar Siswa Pada Mata Pelajaran Sejarah Kelas $X$ di SMA Negeri 3 Palembang

Sarinah, Nur Ahyani, Ahmad Zamhari

Pengaruh Model Pembelajaran Berbasis Masalah (PBM) Terhadap Hasil Belajar Siswa Pada Mata Pelajaran IPS Terpadu (Sejarah) Kelas VIII di SMP Negeri 2 Palembang

Neka Dapistri, Nur Ahyani, Ahmad Zamhari

Penerapan Media Pembelajaran Menggunakan Google Earth Dalam Materi Kondisi Masyarakat Indonesia Pada Masa Penjajahan Terhadap Hasil Belajar Siswa Pada Mata Pelajaran IPS Terpadu di SMP Quraniah Palembang

Tri Nur Ariani, Eva Dina Chairunisa, Ida Suryani

Perkembangan Sosial Budaya Suku Jawa di Desa Kapasan Tegalrejo BK $X$ Kecamatan Belitang Kabupaten Ogan Komering Ulu Timur Sebagai Sumber Pembelajaran Sejarah di SMA Muhammadiyah 2 Karang Tengah

Ratna Puspita Dewi, Sukardi, Mirza Fansyuri

Pengembangan E-Modul Pembelajaran Sejarah Tokoh-Tokoh Pembangunan

Susi Susanti, Eva Dina Chairunisa

Peran Pendidikan Sejarah Dalam Membentuk Karakter Bangsa

Sukardi, Jeki Sepriady

Sejarah Pengajaran Mantra Melayu di Tengah Perubahan Masyarakat Besemah Muhamad Idris, Eva Dina Chairunisa, Jeki Sepriady

Pengembangan Media Audio Visual Sejarah Kolonialisme Barat di Indonesia Materi Benteng Marlborough Bengkulu Hamza Kurniawan 


\section{Kalpataru}

Jurnal Sejarah dan Pembelajaran Sejarah

Volume 6, Nomor 2, Desember 2020

\section{Chief Editor}

Drs. Sukardi, M.Pd.

\section{Editor}

Dr. Muhamad Idris, M.Pd.

Eva Dina Chairunisa, M.Pd.

Jeki Sepriady, S.Pd.

\begin{tabular}{ll}
\multicolumn{2}{c}{ Reviewer } \\
Dr. Tahrun, M.Pd. & (Universitas PGRI Palembang) \\
Drs. Supriyanto, M.Hum. & (Universitas Sriwijaya Palembang) \\
Dra. Retno Purwati, M.Hum. & (Balai Arkeologi Sumatera Selatan) \\
Dr. Nor Huda Ali, M.Ag., M.A. & (Masyarakat Sejarawan Indonesia Sumsel) \\
Dr. Budi Agung Sudarman, S.S., M.Pd. & (Balai Bahasa Provinsi Sumatera Selatan) \\
Dr. Purmansyah, M.A. & (Universitas Muhammadiyah Palembang)
\end{tabular}

Alamat Redaksi

Program Studi Pendidikan Sejarah

Fakultas Keguruan dan IImu Pendidikan Universitas PGRI Palembang

Telp. 0711-510043

Email: jurnalkalpatarusejarah@gmail.com

Website: https://jurnal.univpgri-palembang.ac.id/index.php/Kalpa 


\section{Kalpataru}

JURNAL SEJARAH DAN

PEMBELAJARAN SEJARAH

Terbit dua kali setahun pada Juli dan Desember

Diterbitkan oleh:

Program Studi Pendidikan Sejarah

Jurusan Pendidikan IPS

Fakultas Keguruan

dan IImu Pendidikan

Universitas PGRI Palembang

\section{Gambar Cover:}

Pohon Kalpataru

Candi Prambanan

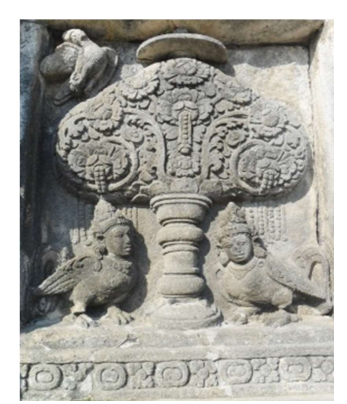

Koleksi: Muhamad Idris 


\section{DAFTAR ISI}

Pengaruh Model Pembelajaran Student Facilitator and Explaining Terhadap Hasil Belajar Siswa Pada Mata Pelajaran Sejarah Kelas X di SMA Negeri 3 Palembang

Sarinah, Nur Ahyani, Ahmad Zamhari 83-89

Pengaruh Model Pembelajaran Berbasis Masalah (PBM) Terhadap Hasil Belajar Siswa Pada Mata Pelajaran IPS Terpadu (Sejarah) Kelas VIII di SMP Negeri 2 Palembang

Neka Dapistri, Nur Ahyani, Ahmad Zamhari..... 90-95

Penerapan Media Pembelajaran Menggunakan Google Earth Dalam Materi Kondisi Masyarakat Indonesia Pada Masa Penjajahan Terhadap Hasil Belajar Siswa Pada Mata Pelajaran IPS Terpadu di SMP Quraniah Palembang

Tri Nur Ariani, Eva Dina Chairunisa, Ida Suryani $96-101$

Perkembangan Sosial Budaya Suku Jawa di Desa Kapasan Tegalrejo BK X Kecamatan Belitang Kabupaten Ogan Komering Ulu Timur Sebagai Sumber Pembelajaran Sejarah di SMA Muhammadiyah 2 Karang Tengah

Ratna Puspita Dewi, Sukardi, Mirza Fansyuri. $102-109$

Pengembangan E-Modul Pembelajaran Sejarah Tokoh-Tokoh Pembangunan Pacsa Kemerdekaan di Sumatera Selatan

Susi Susanti, Eva Dina Chairunisa 110-113

Peran Pendidikan Sejarah Dalam Membentuk Karakter Bangsa

Sukardi, Jeki Sepriady $114-117$

Sejarah Pengajaran Mantra Melayu di Tengah Perubahan Masyarakat Besemah Muhamad Idris, Eva Dina Chairunisa, Jeki Sepriady..... 118-127

Pengembangan Media Audio Visual Sejarah Kolonialisme Barat di Indonesia Materi Benteng Marlborough Bengkulu

Hamza Kurniawan. 128-135 
Kalpataru, Volume 6, Nomor 2, Desember 2020 (96-101)

\title{
PENERAPAN MEDIA PEMBELAJARAN MENGGUNAKAN GOOGLE EARTH DALAM MATERI KONDISI MASYARAKAT INDONESIA PADA MASA PENJAJAHAN TERHADAP HASIL BELAJAR SISWA PADA MATA PELAJARAN IPS TERPADU DI SMP QURANIAH PALEMBANG
}

\author{
Tri Nur Ariani \\ Mahasiswa Program Studi Pendidikan Sejarah, FKIP Universitas PGRI Palembang \\ Email: trinurariani01@gmail.com \\ Eva Dina Chairunisa \\ Dosen Program Studi Pendidikan Sejarah, FKIP Universitas PGRI Palembang \\ Email: evadinachairunisa_si@univpgri-palembang.ac.id \\ Ida Suryani \\ Dosen Program Studi Pendidikan Sejarah, FKIP Universitas PGRI Palembang \\ Email: idasuryani_si@univpgri-palembang.ac.id
}

\begin{abstract}
ABSTRAK
Media pembelajaran pada masa sekarang sangat banyak digunakan, karena kurikulum yang baru yakni kurikulum 2013 mewajibkan siswanya lebih aktif di dalam kelas dan guru sebagai perantara untuk mereka. Dizaman sekarang banyak guru yang telah menggunakan berbagai macam media agar siswa juga tidak merasakan jenuh saat proses belajar mengajar, agar mereka dapat melihat potensi siswa yang diajar pada saat kelas berlangsung. Google Earth yang artinya "gambaran bumi dari berbagai sisi" yaitu siswa dapat menjadi guru bagi temannya apabila mereka mengerti meteri yg teleh dijelaskan oleh gru lalu guru memberi instruksi pada siswa untuk berdiri kedepan dan menjelaskan dengan cara mereka agar dapat membantu temantemannya yang kurung memahami miteri yang telah dijilaskan oleh guru tersebut. Dalam pembelajaran IPS Terpadu sendiri metode ini sangat kooperatif bagi guru IPS Terpadu dan dapat divariasikan dengan ini memberi tantangan bagi para siswa yaitu siswa yang mengerti langsung dapat kedepan kelas dan menjelaskan kembali apa yang telah mereka ketahui dan teman-teman mereka dapat menambahi materi yang menurut mereka dapat ditambahi.
\end{abstract}

Kata Kunci: Media Pembelajaran, Google Earth, Hasil Belajar.

\section{A. PENDAHULUAN}

Pendidikan adalah suatu proses yang utama untuk kemajuan suatu peradaban yang menjamin kelangsungan hidup dalam suatu bangsa tersebut. Begitupun dengan pendidikan yang ada di Indonesia yang merupakan faktor utama untuk mengembangkan masyarakat Indonesia (Kurniasih, 2014:1). Oleh sebab itu pendidikan wajib berorientasi untuk sebuah perubahan agar lebih baik dan sistematis.

Pendidikan dapat dilihat secara umum yang bertujuan untuk menjadikan peserta didik agar lebih memahami suatu inti dari sebuah pengetahuan yang telah diajarkan dari pendidik dan menanamkan dalam kehidupan seharihari. Cara yang sebaiknya digunakan untuk mewujudkan tujuan pendidikan yaitu dengan meningkatkan mutu pendidikan, dan mutu pendidikan yang berada di sekolah meningkatkan kualitas mulai dari segi pengetahuan namun harus meningkatkan keterampilan yang kelak agak berguna dikemudian hari.

Pembelajaran adalah unsur yang sangat mendasar dari jenjang pendidikan dan suatu proses kegiatan pembelajaran yang berada dalam suatu kelas itu merupakan kegiatan yang sangat menentukan suatu keberhasilan mencapai tujuan pendidik. Oleh karena itu, pemahaman yang benar yang berkaitan dengan arti pembelajaran itu sangat dibutuhkan guru yang mampu dan mengerti keadaan kelas. Tujuan untuk mencapai suatu keberhasilan dalam suatu proses pembelajaran merupakan tugas utama seorang guru menyelenggaran pembelajaran dengan efektif 


\section{Kalpataru, Volume 6, Nomor 2, Desember 2020 (96-101)}

dan guru juga harus mengetahui hakikat belajar (Wassid, 2011:1).

Google Erath merupakan sebuah program Globe Virtual yang biasa disebut Earth Viewer. Google Earth memetakan bumi dari berbagai posisi yang disimpulkan dari sebuah pemetaan satekit, Globe GIS 3D dan foto ukuran. Google Earth merupakan sebuah aplikasi yang mencakup keseluruhan peta dunia. Kita mampu hanya dengan mengetik nama tempat maupun sebuah lokasi yang kita inginkan maka akan terlihatlah sebuh gambar daerah tersebut dengan lebih cepat dan lebih efisien. Google Earth juga banyak mempunyai banyak keunggulan sebagai media pembelajaran sejarah, dengan menggunakan Google Earth peserta didik mampu melihat dunia secara praktis dari atas hanya menggunakan hitungan detik mampu mencapai lokasi yang di inginkan (Ardyodyantoro, 2014:4).

Google Earth adalah sebuah program Globe Virtual yang disebut dengan Earth Viewer yang dibuat oleh Keyhole, Inc. Program ini adalah suatu program yang memetakan suatu bumi dari superimposisi suatu gambar yang dikumpulkan dari pemetaan satelit (Arsyad, 2011:15).

Berdasarkan pengertian di atas, maka dapat disimpulkan bahwa Google Earth adalah suatu aplikasi untuk memetakan bumi dari berbagai posisi, Google Earth juga merupakan aplikasi yang mencakup keseluruhan peta diseluruh dunia, Google Earth dibuat oleh keyhole dan Inc.

Kelebihan media pembelajaran menggunakan Google Earth adalah:

1. Proses pembelajaran menjadi lebih interaktif.

2. Proses pembelajaran menjadi lebih jelas dan menjadi lebih menarik.

3. Meningkatkan kualitas hasil belajar.

4. Dapat menumbuhkan sikap positif dan sikap aktif peserta didik terhadap sebuah materi yang diajarkan.

5. Efisiensi dalam proses belajar mengajar baik dari segi waktu dan tenaga.

6. Mengubah peran guru yang lebih positif dan lebih produktif.
Kelemahan media pembelajaran menggunakan Google Earth adalah:

1. Sarana dan prasarana yang dibutuhkan untuk menggunakan media Google Earth mahal sehingga sangat sulit untuk dikembangkan di akademik.

2. Gambar yang dihasilkan dari satelit tidak ditampilkan secara sama dengan lokasi.

3. Google earth hanya mampu bekerja secara efektif apabila digunakan pada perangkat komputer yang memadai.

\section{B. METODE PENELITIAN}

Metode penelitian adalah suatu cara yang digunakan peneliti untuk mengumpilkan data penelitiannya (Arikunto, 2014:203). Sedangkan menurut Sugiyono (2015:107) metode eksperimen yaitu mencari pengaruh dalam perlakuan tertentu dalam kondisi yang terkendali.

Peneliti menggunakan metode Quasi Exsperiment dalam penelitian ini. Eksperimen yaitu suatu teknik untuk mencari sebab dan akibat antara dua faktor yang telah disengaja ditimbulkan keberadaannya oleh penelitidengan mengurangi suatu faktor yang mengganggu.

\section{HASIL DAN PEMBAHASAN}

\section{Hasil Uji Validitas dengan Excel}

\begin{tabular}{|c|c|c|c|}
\hline $\begin{array}{c}\text { No } \\
\text { Soal }\end{array}$ & $\mathbf{r}_{\text {hitung }}$ & $\mathbf{r}_{\text {tabel }}$ & Keterangan \\
\hline 1 & 0,508736 & 0,361 & Valid \\
\hline 2 & 0,056896 & 0,361 & Tidak Valid \\
\hline 3 & 0,498614 & 0,362 & Valid \\
\hline 4 & 0,350105 & 0,361 & Tidak Valid \\
\hline 5 & 0,464528 & 0,361 & Valid \\
\hline
\end{tabular}

Untuk perhitungan selengkapnya dapat dilihat pada lampiran dan masing-masing $r_{\text {hitung }}$ harga $r_{\text {tabel }}$ untuk taraf kesalahan 5\% dengan $n$ $=31$ diperoleh $r$ tabel $=0,361$ jika $r$ hitung $>r$ tabel maka item tersebut tidak valid.

Dari hasil korelasi terdapat soal nomor 2, 4 yang tidak layak untuk diujikan, maka soal nomor 1, 3, 5yang akan diujikan di kelas eksperimen dan kelas kontol yaitu soal yang valid. 


\section{Uji Reabilitas}

Dari hasil perhitungan dapat diketahui reabilitas butir soal sebesar 0,741 . Menurut Wiratna Sudjerweni (2014), kuisioner dikatakan dengan reabilitas apabila nilai cronbach alpha $>0,6$ maka nilai noronbach alpha 0,741 $<0,6$ maka data yang diteliti realibilitas, untuk lebih jelasnya maka dapat dilihat pada tabel dibawah ini:

\section{Hasil Uji Reabilitas}

\begin{tabular}{|l|l|}
\hline Cronbach's Alpha & N Of Items \\
\hline .741 & \multicolumn{1}{|c|}{5} \\
\hline
\end{tabular}

(Sumber: Output Spss 15.0 For Windows)

\section{Ujian Normalitas}

a. Menghitung rentang $(\mathrm{R})$ data

Data terbeesar - data terkecil

$$
\begin{aligned}
\text { Rentang }(\mathrm{R}) & =100-70 \\
& =30
\end{aligned}
$$

b. Menghitung banyak kelas interval (BK)

$$
\begin{aligned}
\text { BK } & =1+3,3 \log n \\
& =1+3,3 \log 31 \\
& =1+3,3(1,49) \\
& =1+4,91 \\
& =5,91 \text { (dibulatkan } 6)
\end{aligned}
$$

c. Menghitung panjang kelas interval (i)

Panjang interval (i)

$$
\begin{aligned}
=\frac{\text { rentang }(R)}{\text { banyak kelas interval }(B K)} \\
=\frac{30}{6} \\
=5
\end{aligned}
$$

d. Tabel data distribusi frekuensi

\section{Distribusi Frekuensi Nilai Tes Akhir pada} kelas Eksperimen

\begin{tabular}{|c|c|c|c|c|c|}
\hline $\begin{array}{c}\text { Interval } \\
\text { Nilai Tes }\end{array}$ & $\boldsymbol{f}_{\boldsymbol{i}}$ & $\boldsymbol{x}_{\boldsymbol{i}}$ & $\boldsymbol{f}_{\boldsymbol{i}} \cdot \boldsymbol{X}_{\boldsymbol{i}}$ & $\boldsymbol{x}_{\boldsymbol{i}}^{\mathbf{2}}$ & $\boldsymbol{f}_{\boldsymbol{i}} \cdot \boldsymbol{X}_{\boldsymbol{i}}^{\mathbf{2}}$ \\
\hline $70-75$ & 2 & 72,5 & 145 & 5,256 & 10,512 \\
\hline $76-81$ & 18 & 78,5 & 1,413 & 6,162 & 119,916 \\
\hline $82-87$ & 9 & 84,5 & 760,5 & 7,140 & 64,26 \\
\hline $88-93$ & 1 & 90,5 & 90,5 & 8,190 & 8,190 \\
\hline $94-100$ & 1 & 96,5 & 96,5 & 9,312 & 9,312 \\
\hline Jumlah & 31 & 422,5 & 1,094 & 9,339 & 212,19 \\
\hline
\end{tabular}

e. Menghitung Rata-rata atau Mean (x)

$$
x=\frac{\sum \int X_{i}}{\int i}=\frac{1,094}{31}=35,3
$$

f. Menentukan Simpangan Baku (s)

$$
\begin{aligned}
S & =\sqrt{\frac{n \sum \int x_{i}^{2}-\left(\int x_{i}\right)^{2}}{n \cdot(n-1)}} \\
& =\sqrt{\frac{31 \cdot 212,19-(1,094)^{2}}{31 \cdot(31-1)}} \\
& =\sqrt{\frac{6,576}{930}} \\
& =\sqrt{7,07} \\
& =2,65
\end{aligned}
$$

g. Membuat frekuensi yang diharapkan dengan jalan:

1. Membentuk batas kelas yaitu angaka nilai pada kelas interval pertama dikurangi 0,5 kemudian angka nilai kanan kelas interval ditambah 0,5 . Sehingga di dapat 69,$5 ; 81,5 ; 81,5$; 93,5; 93,5 .

2. Mencari nilai Z-score untuk kelas interval menggunakan rumus:

$$
\begin{aligned}
& Z=\frac{\text { batas kelas }-x}{S} \\
& Z_{1}=\frac{69,5-35,3}{2,65}=12,8 \\
& Z_{2}=\frac{81,5-35,5}{2,65}=17,3 \\
& Z_{3}=\frac{81,5-35,5}{2,65}=17,3 \\
& Z_{4}=\frac{93,5-35,5}{2,65}=21,8 \\
& Z_{5}=\frac{93,5-35,5}{2,65}=21,8
\end{aligned}
$$

3. Mencari lias $0-Z$ dari tabel kurve normal dari $0-Z$ dengan angka untuk batas kelas, sehingga dapat 0,3997 ; 0,$4573 ; 0,4573 ; 0,4854 ; 0,4854$.

4. Mencari luas tiap kelas interval dengan cara mengurangi angka-angka $0-\mathrm{Z}$, angka baris yang pertama dikurangi angka baris yang ke dua, angka baris yang kedua dikurangi angka baris yang ketiga dan seterusnya. Tapi kecuali angka yang berbeda pada baris paling tengah ditambah angka pada baris berikutnya.

$$
\begin{aligned}
0,3997-0,4573 & =-0,0576 \\
0,4573-0,4573 & =0 \\
0,4573-0,4854 & =-0.0281 \\
0,4854-0,4854 & =0
\end{aligned}
$$

5. Mencari frekuensi yang diharapkan (fe) dengan cara mengalihkan luas tiap 


\section{Kalpataru, Volume 6, Nomor 2, Desember 2020 (96-101)}

interval dengan jumlah responden $(n=$ 31) sehingga dapat:

$-0,0576 \times 31=-1.7856$

$0 \times 31=0$

$-0.0281 \times 31=-0,8711$

$0 \times 31=0$

6. Mencari Chi Kuadrat ( $X^{2}$ hitung $)$ menggunakan rumus sebagai berikut:

$$
\begin{aligned}
& \left(X^{2}\right)=\sum \frac{(f o-f e)^{2}}{f e} \\
& X^{2} \\
= & \frac{(2-1.7856)^{2}}{1.7856}+\frac{(18-0)^{2}}{0} \\
& +\frac{(9-0,8711)^{2}}{0,8711}+\frac{(1-0)^{2}}{0} \\
& +\frac{(1-0)^{2}}{0} \\
= & 0,025+324+75,856+1+1 \\
= & 401,881
\end{aligned}
$$

7.

$$
\text { embandingkan ( } \left.\mathrm{X}^{2} \text { hitung }\right) \text { dengan }\left(\mathrm{X}^{2} \text { tabel }\right)
$$

$\mathrm{db}=\mathrm{k}-3=7-3=4$ dan $\alpha=0,05 \mathrm{di}$ dapat $X^{2}$ tabel $=9,488$

Kaidah Keputusan:

Jika, $X^{2}$ hitung $\geq X^{2}$ tabel, maka distribusi data tidak normal

Jika, $\mathrm{X}^{2}$ hitung $\leq \mathrm{X}^{2}$ tabel, maka distribusi data normal

Ternyata $X^{2}$ hitung $<X^{2}$ tabel atau 401,881 < 9,488 , jadi pada penelitian ini data yang diperoleh $X^{2}$ hitung yaitu 1,90 lebih kecil dari $X^{2}$ tabel yaitu 9,488 . maka dapat disimpulkan bahwa hasil tes belajar ips terpadu dalam penelitian ini distribusi Normal.

\section{Uji Homogenitas}

Dalam penelitian ini uji homogenitas data dengan menggunakan SPSS 15.0 dengan levene statistic. Data dinyatakan homogen apabila nilai signifikan $>0,05$ maka data varians diterima. Jika nilai segnifikan $<0,05$ maka data varians ditolak atau tidak homogen.

Tes Homogenitas Varians

\begin{tabular}{|c|c|c|c|}
\hline $\begin{array}{c}\text { Leven } \\
\text { Statistic }\end{array}$ & df1 & df2 & Sig. \\
\hline
\end{tabular}

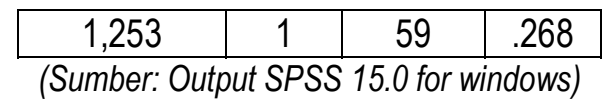

Langkah-langkah dalam pengambilan keputusan:

1.

\section{ipotesis}

Ho : Varian data homogen

$\mathrm{Ha}$ : Varian data tidak homogen

2.

ata penganmbilan keputusan

Probabilitas $>0,05$ maka Ho diterima

Probabilitas $<0,05$ Ha ditolak

3.

eputusan

Berdasarkan uji omogenitas tabel diatas dapat kita lihat bahwa nilai signifikan hasil yaitu 268 dengan $\alpha=0,05$ karena 268 lebih besar. Maka data tersebut bersifat homogen (268 > $0,05)$. Maka dapat disimpulkan Bahwa hasil tes akhir dari pembelajaran ips terpadu dalam penelitian yaitu bersifat homogen.

\section{Uji Hipotesis}

Uji hipotesis dilakukan menggunakan ttest untuk menguji hipotesis menggunakan rumus sebagai berikut:

$$
\mathrm{t}=\frac{X 1-X 2}{\sqrt{\frac{s^{2}}{n_{1}}+\frac{s_{2}^{2}}{n_{2}}}} \text { (Rumus Separated Varians) }
$$

\section{a. Kelas Kontrol}

Distribusi Frekuensi Kelas Kontrol

\begin{tabular}{|c|c|c|c|c|c|c|}
\hline No & $\begin{array}{c}\text { Kelas } \\
\text { Interval }\end{array}$ & $\mathbf{F i}$ & $\mathbf{X i}$ & $\mathbf{F i} . \mathbf{X i}$ & $\mathbf{X i}^{2}$ & Fi . Xi $^{2}$ \\
\hline 1 & $55-60$ & 3 & 57,5 & 172,5 & 3,306 & 9.198 \\
\hline 2 & $61-66$ & 7 & 63,5 & 444.5 & 4,032 & 28.224 \\
\hline 3 & $67-72$ & 10 & 69,5 & 695 & 4,830 & 48.3 \\
\hline 4 & $73-78$ & 10 & 75,5 & 755 & 5,700 & 57 \\
\hline & Jumlah & 30 & 266 & 2,067 & 17,868 & 142.722 \\
\hline
\end{tabular}

Mean (x)

$x=\frac{\sum \int X i}{\int i}=\frac{2,067}{30}=68.9$

Simpangan baku

$$
\begin{aligned}
S & =\sqrt{\frac{n \sum \int x \boldsymbol{i}^{2}-\left(\int \boldsymbol{x i}\right)^{2}}{\boldsymbol{n}(\boldsymbol{n}-\mathbf{1})}} \\
& =\sqrt{\frac{30142.722-(2,067)^{2}}{30(30-)}} \\
& =\sqrt{\frac{4,281,660-4,272,489}{870}}
\end{aligned}
$$


Kalpataru, Volume 6, Nomor 2, Desember 2020 (96-101)

$$
\begin{aligned}
& =\sqrt{\frac{9,171}{870}} \\
& =\sqrt{10.54}=3.2
\end{aligned}
$$

Varians ( $\left.\mathrm{S}^{2}\right)$

$(32)^{2}=10,24$

Distribusi frekuensi kelas eksperimen

\begin{tabular}{|c|c|c|c|c|c|c|}
\hline No & $\begin{array}{c}\text { Kelas } \\
\text { Interval }\end{array}$ & $\mathrm{F}$ & $\mathrm{Xi}$ & $\mathrm{F} \mathrm{Xi}$ & $\mathrm{Xi}^{2}$ & Fxi $^{2}$ \\
\hline 1 & $70-75$ & 2 & 72,5 & 145 & 5,256 & 10,512 \\
\hline 2 & $76-81$ & 18 & 78,5 & 1,413 & 6,162 & 119,916 \\
\hline 3 & $82-87$ & 9 & 84,5 & 760,5 & 7,140 & 64,26 \\
\hline 4 & $88-93$ & 1 & 90,5 & 90,5 & 8,190 & 8,190 \\
\hline 5 & $\begin{array}{c}94- \\
100\end{array}$ & 1 & 96,5 & 96,5 & 9,312 & 9,312 \\
\hline & Jumlah & 31 & 422,5 & 1,094 & 9,339 & 212,19 \\
\hline
\end{tabular}

Mean (x)

$x=\frac{\sum \int X i}{\int i}=\frac{1,094}{31}=35.2$

Simpangan baku

$$
\begin{aligned}
S & =\sqrt{\frac{n \sum \int x i^{2}-\left(\int x i\right)^{2}}{n(n-1)}} \\
& =\sqrt{\frac{31212,19-(1,094)^{2}}{31(31-1)}} \\
& =\sqrt{\frac{6,577.89-113,776}{930}} \\
& =\sqrt{\frac{6,464.114}{930}} \\
& =\sqrt{69,50}=8,3
\end{aligned}
$$

Varians $\left(\mathrm{S}^{2}\right)$

$(83)^{2}=68,89$

\section{Data Nilai Kelas Ekperimen dan Kelas}

Kontrol

\begin{tabular}{|r|r|r|}
\hline $\begin{array}{c}\text { Nilai } \\
\text { Sampel }\end{array}$ & Eksperimen & Kontrol \\
\hline $\mathrm{S}^{2}$ & 68,89 & 10,24 \\
\hline $\mathrm{X}$ & 35.2 & 68.9 \\
\hline $\mathrm{N}$ & 31 & 30 \\
\hline
\end{tabular}

Langkah-langkah Pengujian Hipotesis:

a. Menentukan Hipotesis

Ho: tidak ada pengaruh menggunakan media Google Earth terhadap hasil belajar siswa pada mata pelajaran ips terpadu di SMP Quraniah Palembang.

Ha: ada pengaruh menggunakan media Google Earth terhadap hasil belajar siswa pada mata pelajaran ips terpadu di SMP Quraniah Palembang.

b. Kriteria Pengujian

Jika $t_{\text {hitung }}>t$ tabel maka tolak $\mathrm{Ho}$

Jika $t_{\text {nitung }}<\mathrm{t}_{\text {tabel }}$ maka diterima $\mathrm{Ha}$

c. Menentukan taraf signifikan $\alpha=0,05$

d. Menghitung $t_{\text {hitung }}$ dan $t_{\text {tabel }}$

$$
\begin{aligned}
t \text { test } & =\frac{X_{1}-X_{2}}{\sqrt{\frac{s_{1}^{2}}{n_{1}}+\frac{s_{1}^{2}}{n_{2}}}} \\
& =\frac{35,2-68,9}{\sqrt{\frac{68,89}{31}+\frac{10,24}{30}}} \\
& =\frac{23,31}{\sqrt{2,22+2,92}} \\
& =\frac{23,31}{\sqrt{5,14}} \\
& =\frac{23,31}{2,26}=10,314
\end{aligned}
$$

Dengan taraf signifikan $\alpha=5 \%$ kemudian dicari $t$ tabel pada tabel distribusi $t$ dengan ketentuan $\mathrm{db}=\mathrm{n} 1+\mathrm{n} 2-2=31+30-2=$ 59 Sehingga nilai $t_{\text {tabel }}=1,67109$

e. Membandingkan $t$ hitung dengan $t$ tabel Berdasarkan hasil perhitungan diatas didapat $t$ hitung $=10,314$ sedangkan $t$ tabel $=1,67109$ sehingga diperoleh $t$ hitung $=$ $10,314>t$ tabel $=1,67109$ jadi Ho ditolak dan Ha diterima.

f. Pengambilan keputusan

Karena $t_{\text {hitung }}=10,314>t$ tabel $=1,67109$ maka ada pengaruh penggunaan media Google Earth terhadap hasil belajar siswa pada mata pelajaran ips terpadu di SMP Quraniah Palembang.

\section{SIMPULAN}

Penerapan media Google Earth belum pernah diterapkan di SMP Quraniah Palembang. Peneliti menggunakan sampel pada penelitian ini yaitu secara random sampling atau yang bisa disebut dengan sampel acak. Jika sampel pada penelitian ini kelas VIII.2 sebagai kelas eksperimen yang berjumlah 31 siswa, sedangkan sampel kelas VIII.1 sebagai kelas kontrol yang berjumlah 30 siswa. Variabel $\mathrm{X}$ (variabel bebas) yaitu media 


\section{Kalpataru, Volume 6, Nomor 2, Desember 2020 (96-101)}

pembelajaran menggunakan aplikasi Google Earth dan variabel $Y$ (variabel terikat) yaitu hasil belajar.

Untuk mengetahui pengaruh penggunaan media pembelajaran menggunakan google erath terhadap hasil belajar siswa pada mata pelajaran ips terpadu menggunakan t-tes, sebelum menggunakan rumus ini data penelitian ini harus memenuhi uji persyaratan yakni distribusi normal dan data yang bersifat homogen. Dengan diperoleh $\mathrm{X}^{2}$ hitung $<X^{2}$ tabel atau 401,881 $<9,488$, jadi pada penelitian data yang didapatkan $\mathrm{X}^{2}$ hitung adalah 401,881 lebih kecil dari $X^{2}$ tabel adalah 9,488. Maka dapat disimpulkan bahwa hasil tes akhir pembelajaran IPS Terpadu pada penelitian ini berdistrinusi normal. Sedangkan uji homogenitas diperoleh dari tabel dilihat bahwa nilai signifikan hasilnya lebih besar 0,268 dengan $\alpha=0,05$ karena 0,268 lebih besar maka data tersebut bersifat homogen $(0,268>$ $0,05)$. Maka dapat disimpulkan bahwa hasil tes akhir dari hasil pembelajaran ips terpadu dalam penelitian ini bersifat homogen.

Hasil analisis hipotesis menggunakan independent sampel test menunjukan bahwa ada pengaruh penggunaan media pembelajaran menggunakan media Google Earth terhadap hasil belajar siswa pada mata pelajaran ips terpadu di SMP Quraniah Palembang. Karena $t_{\text {nitung }}=10,314>t_{\text {tabel }}=$ 1,67109 maka ada pengaruh dalam penerapan media pembelajaran menggunakan media Google Earth pada mata pelajaran ips terpadu di SMP Quraniah Palembang.

\section{DAFTAR PUSTAKA}

Ardyodyantoro. 2014. Pemanfaatan Google Earth dalam Pembelajaran Geografi Untuk Meningkatkan Hasil Belajar Siswa Kelas $X$ SMA Widya Kutoarjo. Yogyakarta: Universitas Negeri Yogyakarta.

Arikunto, Suharsimi. 2014. Prosedur Peenelitian Suatu Pendekatan Praktik. Jakarta: Rineka Cipta.
Arsyad, Azhar. 2011. Media Pembelajaran. Jakarta: PT Raja Grafindo Persedia.

Kurniasih, Imas dan Sani, Berlin. 2014. Impelmentasi Kurikulum 2013 Konsep \& Penerapan. Surabaya: Kata Pena.

Sugiyono. 2015. Metode Penelitian Tindakan Komperehensif. Bandung: Alfabeta.

Wassid, Isskandar dan Dadang Sunendar. 2011. Strategi Pembelajaran Bahasa. Bandung: PT Remaja Rosdakarya. 


\section{KETENTUAN PENULISAN ARTIKEL JURNAL KALPATARU}

1. Naskah berbahasa Indonesia yang disempurnakan bertemakan kesejarah yang meliputi hasil penelitian sejarah, pengajaran sejarah dan penelitian kebudayaan.

2. Naskah harus asli dan belum pernah dimuat dalam media lain. Naskah dapat berupa hasil penelitian/artikel kajian konseptual yang ditulis oleh perorangan dan atau kelompok.

3. Naskah ditulis dengan cara-cara yang sesuai dengan ketentuan penulisan artikel ilmiah menggunakan bahasa Indonesia yang baku, berupa ketikan, beserta soft file dalam CD-RW atau dengan mengirimkan email pada redaksi jurnal Kalpataru dengan alamat jurnalkalpatarusejarah@gmail.com, spasi tunggal, jenis huruf arial narrow ukuran 12, dengan panjang naskah antara 8-15 halaman pada kertas A4.

4. Artikel hasil penelitian memuat:

JUDUL

Nama Penulis

Abstrak

A. PENDAHULUAN

B. METODE PENELITIAN

C. HASIL DAN PEMBAHASAN

D. SIMPULAN

DAFTAR PUSTAKA
: XXX (HURUF KAPITAL)

: (disertai jabatan, institusi, dan email)

: (Bahasa Indonesia yang memuat 100-200 kata diikuti kata kunci, dengan jenis huruf arrial narrow dan ukuran huruf 11 serta dicetak miring).

: (memuat latar belakang masalah, tinjauan pustaka secara ringkas, masalah penelitian, dan tujuan penelitian).

5. Artikel Kajian Konseptual memuat:

JUDUL

Nama Penulis

Abstrak

PENDAHULUAN

Sub Judul

Simpulan

DAFTAR PUSTAKA
: (berisi simpulan).

: (berisi pustaka yang dirujuk dalam uraian naskah).

6. Referensi sumber dalam teks artikel ditulis dengan menggunakan side note, contoh (Jalaludin, 1991:79); sementara penulisan daftar pustaka disusun dengan ketentuan. Nama pengarang. Tahun terbit. Judul (dicetak miring). Kota terbit: Nama Penerbit. Contoh: Koentjaraningrat. 2010. Manusia dan Kebudayaan di Indonesia. Jakarta: Djambatan. Daftar pustaka hanya memuat pustaka/sumber yang dirujuk dalam uraian dan disusun menurut abjad tanpa nomor urut.

7. Naskah yang dimuat akan disunting kembali oleh redaksi tanpa mengubah isinya.

8. Naskah yang ditolak (tidak bisa dimuat) akan dikirim kembali ke penulis dengan pemberitahuan tertulis dari redaksi atau melalui email.

9. Penulis yang naskahnya dimuat akan mendapat 1 (satu) majalah nomor yang bersangkutan.

10.Kontak person: Muhamad Idris (081271498618); Eva Dina Chairunisa (082281267851); Jeki Sepriady (085269261780). 